\title{
Predictors of Condom-use among Young Never-married Males in Nigeria
}

\author{
Kolawole Azeez Oyediran', Oluwadaisi Isaac Feyisetan², and \\ Toyin Akpan

\begin{abstract}
'MEASURE Evaluation/JSI, 90 Nelson Mandela Street, Asokoro, Abuja, Nigeria, ${ }^{2}$ Northern Education Initiative, Block I8, Ministry of Education, Shehu Kangiwa Secretariat, Sokoto, Sokoto State, Nigeria, and ${ }^{3}$ AURICLE Services Limited,
\end{abstract} 37A Ladipo Kasumu Street, By Bisi Ogabi Street, Ikeja, Lagos, Nigeria

\begin{abstract}
This study examined the factors that influence condom-use among young never-married males in Nigeria. Such information can help improve the design of a prevention programme for young never-married, especially, males to reduce their vulnerability to sexually transmitted infections (STIs) and HIV/AIDS transmission. Data were derived from the 2003 Nigeria Demographic and Health Survey (NDHS). Analysis of data was restricted to 827 males aged 15-24 years, who had never married or lived together with a woman. Both descriptive and analytical methods were used for assessing the net effects of socioeconomic factors on condom-use. The analysis used logistic regression models for determining the predictors of sexual behaviour and condom-use among young never-married males in Nigeria. About $43 \%$ of the study population was sexually experienced, and the use of a condom remained low. One in five reported the use of a condom at sexual debut. Level of education, place of residence in childhood, urban/rural region, religious affiliation, economic status index, and exposure to mass media were associated with sexual experience and use of protective measures. Economic status index and mass-media exposure were associated with the use of a condom by the respondents during their last sex encounter. About two-fifths (43\%) of the young unmarried Nigerian men were sexually experienced but the condom-use remained low, thus making this sub-group of Nigerian population highly vulnerable to STIs, including HIV/AIDS.
\end{abstract}

Key words: Acquired immunodeficiency syndrome; Condom-use; HIV; Sex behaviour; Sexually transmitted infections; Youth; Nigeria

\section{INTRODUCTION}

Adolescence is a transition period between childhood and adulthood. This is a time when many young people experience critical life-defining changes, such as their first sexual experience, marriage, pregnancy, and parenthood. Initiation of sexual intercourse has been described as a milestone in the physical and psychological development of men and women in all societies (1). This episode in life is taking place in a different socioeconomic context from previous generations. Results of studies revealed that the circumstances of the first sexual encounters of adolescents have immediate and longer-term consequences for their sexual health

Correspondence and reprint requests should be addressed to:

Dr. Kolawole Azeez Oyediran

90 Nelson Mandela Street

Asokoro, Abuja

Nigeria

Email: kboyediran@gmail.com later in life (2-3). Some instances of very early sexual intercourse have been reported to be involuntary-for example, a young person being raped or a victim of incest or turned to prostitution because of financial need $(1,4-5)$. A study in Ibadan, Nigeria, reported that $8 \%$ and $5 \%$ of in-school adolescents and adolescent apprentices respectively in Ibadan reported to have been raped (6). Results of another study in Plateau state showed that $11 \%$ of secondary school students aged 12-21 years had had forced sexual intercourse (7).

Sexual behaviour of adolescents is important not only because of the possible reproductive outcomes but also because risky sexual behaviours, such as unprotected sex and low and inconsistent use of a condom during sexual intercourse, have been associated with HIV infection. Early sexual initiation poses health risks for both young men and women. Most young adults who entered into a sexual relationship for the first time did not use any form of contraception and were ignorant of the conse- 
quences of their acts (8-10) leaving them vulnerable to unintended pregnancies and unplanned parenthood. Results of a study of adolescent sexuality in Peru showed that $38 \%$ of male youths used condom at the time of first intercourse (8). In Ibadan, $43.9 \%$ of in-school adolescents with single parents did not know that pregnancy could result from first coitus (9). The visible consequences of teenage sexual behaviour in Nigeria are high rates of out-of-wedlock pregnancies among adolescents, abortions, and sexually transmitted infections (STIs) which increase the risk of HIV infections (11-15). For example, $42 \%$ of adolescent girls in a rural community in Rivers state had had induced abortion or STIs, including gonorrhoea (12). In Jos (Plateau state), 24\% of patients who attended STI clinics were aged less than 25 years (14). In Calabar (Cross River state), 72\% of patients admitted to hospitals for complications of abortion were aged $12-20$ years (11).

In Nigeria, sexual activity among adolescents is a concern of public-health priority for government officials, donors, and programme managers because of the serious outcomes usually accompanying teenage unprotected sexual exploitation (16-18). This concern is reflected in the growing number of reproductive health interventions aimed at young never-married males that have been implemented in many settings in recent years and increasing level of resources earmarked for such programmes. Results of studies on adolescent sexuality suggest that young Nigerians are becoming sexually active at an earlier age $(9,19-22)$. According to the 2003 Nigeria Demographic and Health Survey (NDHS), 75.5\% of women aged 25-49 years had sexual intercourse by the age of 20 years, and $39.3 \%$ of men aged 25 59 had sexual intercourse by the age of 20 years. In a related analysis of the 1999 NDHS, 31.5\% of unmarried female youths aged 15-24 years were sexually experienced, and the median age of sexual debut was 16.6 years (22). Only one-fifth of these sexually-active unmarried female youths, however, used a condom at the last sexual intercourse, hence making them vulnerable to unplanned parenthood and STIs, including HIV.

Sensitization and information programmes on the consequences of unprotected sexual intercourse, including HIV/AIDS, have been implemented in Nigeria, along with efforts to promote the use of condoms. These programmes have, however, had limited impact in the translation of knowledge about HIV/AIDS and prevention methods into the adoption of healthy sexual behaviour (23). Evi- dence also suggests that adolescents have sex because of peer pressure, curiosity, love, promise of marriage, and to have fun (3,24-25). Given that parents of adolescents do not discuss sexual matters with their offspring, information about sex is largely obtained from peers and garbled, inaccurate literature. Moreover, information provided by mass media is often distorted, and peers tend to be misinformed as they lack adequate and correct knowledge of sexual and reproductive health. Most adolescents, especially males in Nigeria, do not use pregnancy-prevention methods, particularly condom, for a number of reasons. The reasons include misconception that their female partners will not get pregnant; the unavailability of youth-friendly clinics from which they can seek advice on contraceptive methods; and refusal to attend clinics for reproductive health issues due to lack of privacy.

Designing an effective programme to promote responsible reproductive health behaviour among young adults in Nigeria requires a better understanding of the factors relating to their sexual behaviours. Although scholars have documented factors associated with reproductive health behaviour among Nigerian youths, a few of these have examined sexual behaviour of young never-married males and in particular condom-use at sexual debut. This study examined the predictors of condom-use at sexual debut among young never-married males in Nigeria. Condom-use during the first sexual experience warrants special attention in light of the spread of STIs and the HIV/AIDS pandemic and the increase in unwanted and unplanned pregnancies that may lead to discontinuation of schooling. Overall, this paper focused on understanding the factors affecting condom-use by young never-married males at both sexual initiation and the last sexual act.

\section{MATERIALS AND METHODS}

The study used data from the 2003 NDHS. This nationally-representative sample survey covered 7,864 households located in both urban and rural settings. The area-sampling frame for the survey was based on the enumeration area-maps prepared by the National Population Commission (NPC) for conducting the 1991 census. Selection of sample was made in two stages: first, 365 clusters were selected with equal probability. Second, within each of these 365 clusters, a complete listing was done of all residents in sampled households, from which male and female respondents were interviewed. Details of the research design are available in the 2003 NDHS report (26). In total, 7,327 (95\%) of the 7,684 households selected 
for the study were found. The shortfall was largely due to vacant dwelling structures found at the time of survey. Of the 7,327 existing households, 7,225 (99\%) were successfully interviewed. In these households, 7,985 women and 2,572 men were eligible for the individual interviews. However, 7,620 women aged 15-49 years and 2,346 men aged 15-59 years were successfully interviewed, representing a response rate of $95 \%$ and $91 \%$ for women and men respectively. Of the male respondents, 827 (35\%) were aged 15-24 years and had never married or lived together with a woman, and 355 had had sexual experience. Analysis here is restricted to this sub-population.

Analysis focused on four reproductive health behaviours: whether respondents had had sex; whether they had sex in the four weeks before the interview; whether they had used condom at first sexual intercourse and whether condom was used at the last sexual intercourse. Their demographic characteristics were included in the analysis to identify factors for possible intervention and to act as control variables in the analytical models. The characteristics considered were age, the highest level of education completed, place and region of residence, religious affiliation, media exposure, and wealth quintile. Analysis of the first reproductive health behaviour-whether the respondents had had sexual intercourse-was based upon responses provided by all 827 sample respondents. However, analysis of the remaining three reproductive health behaviours was based on 355 respondents who had had sexual intercourse.

Both descriptive and analytical analyses were conducted to ascertain the association and net effect of the background characteristics of the respondents on reproductive health behaviours-sexual activity and condom-use-when controls for the selected background characteristics were introduced. The statistical analyses were undertaken in two phases. Bivariate relationships between each of the selected characteristics/predictors and reproductive health behaviours of interest were established. The statistical significance of difference among categories of discrete reproductive health behaviours was tested through Pearson's chi-square statistic.

Background characteristics for which statistically significant bivariate associations were observed were retained for subsequent multivariate analyses. The four reproductive health behaviours of interest (ever had sex, condom-use at first sex, condomuse at last sex, sexually active in the previous four weeks) were binary outcomes. Logistic regression was used for determining the effects of predictor variables on selected reproductive health behaviours. The logistic regression model also offers ease of interpretation through the use of odds ratios. The logistic regression function has the form In $(p / q)=B_{0}+B_{1} X_{1}+\ldots+B_{k} X_{k^{\prime}}$, where $p$ is the probability that a respondent used a condom during sexual debut or the last sexual act; q (or 1-p) is the probability that the respondent did not use a condom at sexual debut or the last sexual act. $\mathrm{B}_{0}, \mathrm{~B}_{1}, \ldots \mathrm{B}_{\mathrm{k}}$ are regression coefficients, and $\mathrm{X}_{1}, \mathrm{X}_{2}, \ldots \mathrm{X}_{\mathrm{k}}$ are factors. The exponential of the regression coefficients of the parameter estimated gives the odds ratios in the logistic regression models, which is interpreted as the likelihood of condom used under the given scenario

\section{RESULTS}

\section{Profile of respondents}

In total, 827 young never-married males, aged 1524 years, who were interviewed during the 2003 NDHS, were analyzed in the study. Table 1 presents the basic demographic characteristics of the study population. About 54\% of them were aged 15-19 years while the remaining $46 \%$ were aged $20-24$ years. Their median age was 19 years. The survey indicated that more than half of the respondents resided in rural areas, and just little over $47 \%$ had place of residence during childhood in the countryside. Spatial distribution of the study population showed that $52 \%$ of them resided in the north while the remaining $48 \%$ resided in the three regions in the southern part of the country.

About $70 \%$ of the study men had some secondary education. Only $6 \%$ of them had post-secondary education, and $8.6 \%$ had no formal education. Christians constituted a majority (58\%) of the sampled respondents, with three in five young never-married males being Christians. Muslims constituted $41.2 \%$, and less than $1 \%$ was adherent to indigenous religions. Another important background characteristic considered in the analysis was the wealth quintile. The wealth quintile constructed from the household facilities was used as a proxy for economic status. The level of wealth quintile ranged from the first to the fifth quintile, corresponding to the least and most well-off respectively. The wealth quintile revealed that about one in four young never-married males was from households classified in the fifth quintile.

Table 1 reveals a high level of exposure to electronic mass media. Most (94\%) respondents listened to radio at least once in a while, and 59\% of the young never-married males reported listening to radio ev- 


\begin{tabular}{|c|c|c|}
\hline Characteristics & $\begin{array}{c}\text { No. } \\
(\mathrm{n}=827)\end{array}$ & $\%$ \\
\hline \multicolumn{3}{|l|}{ Age-group (years) } \\
\hline $15-19$ & 448 & 54.2 \\
\hline $20-24$ & 379 & $45.819 .0^{*}$ \\
\hline \multicolumn{3}{|l|}{ Place of residence } \\
\hline Urban & 387 & 46.8 \\
\hline Rural & 440 & 53.2 \\
\hline \multicolumn{3}{|l|}{ Region of residence } \\
\hline North-central & 160 & 19.3 \\
\hline Northeast & 107 & 12.3 \\
\hline Northwest & 169 & 20.4 \\
\hline Southeast & 113 & 13.7 \\
\hline South-South & 127 & 15.4 \\
\hline Southwest & 151 & 18.3 \\
\hline \multicolumn{3}{|l|}{$\begin{array}{l}\text { Childhood place of } \\
\text { residence }\end{array}$} \\
\hline City & 174 & 21.1 \\
\hline Town & 262 & 31.7 \\
\hline Countryside & 390 & 47.2 \\
\hline \multicolumn{3}{|l|}{ Educational level } \\
\hline No education & 71 & 8.6 \\
\hline Primary & 174 & 21.0 \\
\hline Secondary & 528 & 63.8 \\
\hline Tertiary & 54 & 6.5 \\
\hline \multicolumn{3}{|l|}{ Religious affiliation } \\
\hline Catholic & 167 & 20.2 \\
\hline Protestant & 124 & 15.0 \\
\hline Other Christians & 188 & 22.7 \\
\hline Muslim & 341 & 41.2 \\
\hline Traditional/others & 7 & 0.8 \\
\hline \multicolumn{3}{|l|}{ Wealth quintile } \\
\hline First & 140 & 16.9 \\
\hline Second & 124 & 15.0 \\
\hline Third & 152 & 18.4 \\
\hline Fourth & 213 & 25.8 \\
\hline Fifth & 198 & 23.9 \\
\hline \multicolumn{3}{|l|}{$\begin{array}{l}\text { Frequency of reading } \\
\text { newspapers or maga- } \\
\text { zines }\end{array}$} \\
\hline Never & 392 & 47.5 \\
\hline Less than once a week & 216 & 26.2 \\
\hline At least once a week & 158 & 19.1 \\
\hline Almost every day & 60 & 7.3 \\
\hline \multicolumn{3}{|l|}{$\begin{array}{l}\text { Frequency of watching } \\
\text { television }\end{array}$} \\
\hline Never & 190 & 23.0 \\
\hline Less than once a week & 193 & 23.3 \\
\hline At least once a week & 196 & 23.7 \\
\hline \multirow[t]{2}{*}{ Almost every day } & 247 & 29.9 \\
\hline & & Contd. \\
\hline
\end{tabular}

\begin{tabular}{|c|c|c|}
\hline $\begin{array}{l}\text { Frequency of listening to } \\
\text { radio }\end{array}$ & & \\
\hline Never & 45 & 5.4 \\
\hline Less than once a week & 104 & 12.6 \\
\hline At least once a week & 192 & 23.2 \\
\hline Almost every day & 484 & 58.5 \\
\hline
\end{tabular}

ery day. About a quarter (23\%) had never watched television, and about $30 \%$ watched television every day. The results indicate widespread access of the participants to media.

\section{Sexual behaviour}

Overall, about $43 \%$ of the respondents had ever had sexual intercourse, and the median age at sexual debut was 18 years. About one-fifth of the study population had sexual relations in the month and of those who were sexually experienced, about 47 had sexual relations in the four weeks before interview. Table 2 shows the distribution of sexually-experienced young never-married males and current sexual activity by selected sociodemographic factors.

Results of analysis revealed that the proportions of the respondents who were sexually experienced and those who had sexual intercourse in the previous four weeks before the interview survey increased with age. For instance, one-fourth of the young never-married male respondents aged 15-19 years and $62 \%$ of their older peers aged $20-24$ years had ever had sex. The corresponding figures with respect to sexual activity in the past month were about $45 \%$ and $47 \%$ respectively. Table 2 further reveals that the young never-married males from the southeast commenced sexual activity about six months earlier than their counterparts from the northern and southwestern regions.

Rural residents tended to initiate sexual relations earlier than did urban residents (about a one-year difference) and were slightly more sexually experienced and more sexually active in the last four weeks before the interview. For instance, $45 \%$ of the young never-married rural males were sexually experienced compared to $39.6 \%$ of their urban counterparts. Childhood place of residence somewhat supported the notion of less-frequent sexual activity among those who had some urban exposure. However, the age at sexual debut was generally higher among those with higher level of 


\begin{tabular}{|c|c|c|c|c|}
\hline \multirow[t]{2}{*}{ Characteristics/variable } & \multicolumn{2}{|c|}{$\begin{array}{l}\text { Ever had sex } \\
\quad(\mathrm{n}=827)\end{array}$} & \multicolumn{2}{|c|}{$\begin{array}{l}\text { Sexually active in the last } \\
4 \text { weeks among the } \\
\text { sexually experienced } \\
(\mathrm{n}=355)\end{array}$} \\
\hline & No. & $\%$ & No & $\%$ \\
\hline \multicolumn{5}{|l|}{ Age-group (years) } \\
\hline $15-19$ & 448 & 24.8 & 126 & 44.9 \\
\hline $20-24$ & 379 & 62.1 & 283 & 47.2 \\
\hline \multicolumn{5}{|l|}{ Place of residence } \\
\hline Urban & 387 & 39.6 & 179 & 33.9 \\
\hline Rural & 440 & 45.1 & 230 & 53.8 \\
\hline \multicolumn{5}{|l|}{ Region of residence } \\
\hline North-central & 160 & 52.1 & 86 & 50.9 \\
\hline Northeast & 107 & 47.3 & 59 & 58.5 \\
\hline Northwest & 169 & 25.0 & 54 & 61.4 \\
\hline Southeast & 113 & 43.9 & 56 & 17.0 \\
\hline South-South & 127 & 48.0 & 71 & 51.6 \\
\hline Southwest & 151 & 52.2 & 83 & 27.9 \\
\hline \multicolumn{5}{|c|}{ Childhood place of residence } \\
\hline City & 174 & 35.4 & 66 & 34.7 \\
\hline Town & 262 & 45.5 & 137 & 45.2 \\
\hline Countryside & 390 & 44.0 & 205 & 50.9 \\
\hline \multicolumn{5}{|l|}{ Educational level } \\
\hline No education & 71 & 31.6 & 34 & 57.2 \\
\hline Primary & 174 & 39.6 & 90 & 51.1 \\
\hline Secondary & 528 & 45.1 & 256 & 45.4 \\
\hline Tertiary & 54 & 56.5 & 29 & 29.8 \\
\hline \multicolumn{5}{|l|}{ Religious affiliation } \\
\hline Catholic & 167 & 47.7 & 88 & 40.1 \\
\hline Protestant & 124 & 51.5 & 64 & 52.8 \\
\hline Other Christians & 188 & 46.3 & 100 & 32.4 \\
\hline Muslim & 341 & 37.0 & 153 & 56.5 \\
\hline Traditional/others & 7 & 56.7 & 4 & 27.2 \\
\hline \multicolumn{5}{|l|}{ Wealth quintile } \\
\hline First & 140 & 50.5 & 84 & 60.7 \\
\hline Second & 124 & 35.1 & 55 & 57.5 \\
\hline Third & 152 & 40.6 & 71 & 53.4 \\
\hline Fourth & 213 & 38.7 & 89 & 42.9 \\
\hline Fifth & 198 & 49.1 & 110 & 26.6 \\
\hline \multicolumn{5}{|c|}{ Frequency of reading newspapers or magazines } \\
\hline Never & 392 & 34.2 & 178 & 53.8 \\
\hline Less than once a week & 216 & 51.5 & 111 & 42.9 \\
\hline At least once a week & 158 & 49.8 & 84 & 46.7 \\
\hline Almost every day & 60 & 61.7 & 35 & 25.3 \\
\hline \multicolumn{5}{|c|}{ Frequency of watching television } \\
\hline Never & 190 & 36.9 & 87 & 63.8 \\
\hline Less than once a week & 193 & 47.3 & 103 & 50.7 \\
\hline At least once a week & 196 & 40.5 & 90 & 55.0 \\
\hline \multirow[t]{2}{*}{ Almost every day } & 247 & 45.5 & 128 & 27.6 \\
\hline & & & & Contd. \\
\hline
\end{tabular}




\begin{tabular}{|c|c|c|c|c|}
\hline \multirow[t]{2}{*}{ Characteristics/variable } & \multicolumn{2}{|c|}{$\begin{array}{l}\text { Ever had sex } \\
\quad(\mathrm{n}=827)\end{array}$} & \multicolumn{2}{|c|}{$\begin{array}{l}\text { Sexually active in the } \\
\text { last } 4 \text { weeks ... }(n=355)\end{array}$} \\
\hline & No. & $\%$ & No. & $\%$ \\
\hline \multicolumn{5}{|c|}{ Frequency of listening to radio } \\
\hline Never & 45 & 23.7 & 18 & 64.1 \\
\hline Less than once a week & 104 & 25.5 & 36 & 49.4 \\
\hline At least once a week & 192 & 36.0 & 83 & 51.6 \\
\hline Almost every day & 484 & 50.9 & 271 & 43.6 \\
\hline
\end{tabular}

education compared to those with lower level of education. This finding indicates that young nevermarried males with no formal education started sexual activity two years earlier than those with tertiary education.

Religion is believed to have a profound impact on individual behaviour and views $(27,28)$. Even in the face of modernization and its consequences on cultural practices, religion seems to still shape beliefs about sexual activity. Therefore, young never-married males who were more religious were more likely to hold types of beliefs that may discourage sexual activity. The relationship between religious affiliation and reproductive health behaviour, particularly sexuality, is likely to be mediated by social and demographic factors, such as education of the respondent. Table 2 shows that young never-married Muslim males were less sexually experienced but more sexually active in the month preceeding the survey than their Christian counterparts: about 37\% of young never-married Muslim males in Nigeria reported being sexually experienced compared to $48 \%$ of their counterparts who were Catholic. In addition, Muslim respondents started sexual activity about one year later than Christian respondents and two years later than those adherent to other faiths. A higher proportion of young Muslim men reported being more sexually active in the last four weeks than their Christian counterparts ( $57 \%$ vs $32 \%)$.

Table 2 further shows that the wealth quintiles were inversely associated with being sexually active in the month before the survey. First, those from the first and the fourth wealth quintile started sexual relations one year earlier than those from other wealth quintiles. Level of access to media information was positively related with the level of sexual activity, although the median age at initiation of sex was inversely related with access to information. Respondents with low access to media information started sexual activity almost 12 months earlier than those with better access to information.
In the logistic regression model (Table 3 ), young never-married males aged 20-24 years were (5.49 times) more likely than those aged $15-19$ years to have had sex. The odds of engaging in premarital sex were 1.64 times higher among young nevermarried rural males than their urban counterparts, which is consistent with the findings of earlier studies in Nigeria $(20,22)$. Region of residence was also associated with engaging in premarital sex: compared to young never-married males in the northcentral region, those in the northeast, northwest, and southeast regions were significantly less likely to engage in premarital sex. Those in the northeast were about half as likely to engage in premarital sex compared to those in the north-central states. Young never-married males from households classified into second quintile and fourth quintile were less likely to have premarital sex compared to those from households ranking in the first quintile.

With respect to correlates of current sexual activity in the last four weeks preceding the survey, loresidence, religious affiliation, and frequency of watching television were significantly associated with whether the young never-married males engaged in premarital sex in the last four weeks before the survey. Those who resided in the southeast region were almost four times less likely to engage in sex in the previous four weeks compared to their counterparts from the north-central region.

\section{Condom-use}

About two-fifth (43\%) of the young never-married males in Nigeria were sexually experienced, the level of condom-use among them was low-an indication of a high level of their vulnerability to STIs, including HIV. Seventeen percent of the young never-married males who were sexually experienced used condom at the time of their first sexual act (Table 4). Table 4 shows the percentage distribution of respondents who used a condom at their first sexual experience according to selected 


\begin{tabular}{|c|c|c|c|c|}
\hline \multirow{2}{*}{ Characteristics } & \multicolumn{2}{|c|}{$\begin{array}{l}\text { Sexually experienced } \\
\qquad(\mathrm{n}=355)\end{array}$} & \multicolumn{2}{|c|}{$\begin{array}{l}\text { Sexually active in the } \\
\text { last four weeks }(n=355)\end{array}$} \\
\hline & Odds ratio & $\begin{array}{c}\text { Standard } \\
\text { error }\end{array}$ & Odds ratio & $\begin{array}{c}\text { Standard } \\
\text { error }\end{array}$ \\
\hline \multicolumn{5}{|l|}{ Age-group (years) } \\
\hline $15-19$ & 1.00 & & 1.00 & \\
\hline $20-24$ & $5.49^{\star *}$ & 1.04 & 1.45 & 0.42 \\
\hline \multicolumn{5}{|l|}{ Place of residence } \\
\hline Urban & 1.00 & & 1.00 & \\
\hline Rural & $1.64^{*}$ & 0.42 & 1.49 & 0.55 \\
\hline \multicolumn{5}{|l|}{ Region of residence } \\
\hline North-central & 1.00 & & 1.00 & \\
\hline Northeast & $0.50^{*}$ & 0.18 & 0.78 & 0.35 \\
\hline Northwest & $0.14^{\star *}$ & 0.05 & 0.83 & 0.44 \\
\hline Southeast & $0.46^{*}$ & 0.15 & $0.24^{\star *}$ & 0.12 \\
\hline South-South & 0.75 & 0.25 & 1.54 & 0.63 \\
\hline Southwest & 0.78 & 0.25 & 0.67 & 0.27 \\
\hline \multicolumn{5}{|l|}{ Educational level } \\
\hline No education & 1.00 & & 1.00 & \\
\hline Primary & 1.05 & 0.41 & 2.05 & 1.06 \\
\hline Secondary & 0.64 & 0.26 & 2.32 & 1.31 \\
\hline Post-secondary & 0.53 & 0.31 & 2.39 & 1.92 \\
\hline \multicolumn{5}{|l|}{ Religious affiliation } \\
\hline Catholic & 1.07 & 0.36 & 0.51 & 0.26 \\
\hline Protestant & 0.95 & 0.30 & 0.77 & 0.37 \\
\hline Other Christians & 0.77 & 0.23 & $0.29^{*}$ & 0.16 \\
\hline Muslim & 1.00 & & 1.00 & \\
\hline \multicolumn{5}{|l|}{ Wealth quintile } \\
\hline First & 1.00 & & 1.00 & \\
\hline Second & $0.55^{\star}$ & 0.15 & 0.89 & 0.37 \\
\hline Third & 0.62 & 0.21 & 1.19 & 0.60 \\
\hline Fourth & $0.55^{*}$ & 0.18 & 0.73 & 0.34 \\
\hline Fifth & 0.85 & 0.32 & 0.93 & 0.56 \\
\hline \multicolumn{5}{|c|}{ Frequency of reading newspapers or magazines } \\
\hline Not at all & 0.43 & 0.22 & 1.61 & 0.98 \\
\hline Less than once a week & 0.86 & 0.43 & 1.13 & 0.72 \\
\hline At least once a week & 0.95 & 0.46 & 2.04 & 1.24 \\
\hline Almost every day & 1.00 & & 1.00 & \\
\hline \multicolumn{5}{|c|}{ Frequency of watching television } \\
\hline Not at all & 1.40 & 0.53 & $3.10^{*}$ & 1.68 \\
\hline Less than once a week & $1.87^{*}$ & 0.58 & 1.67 & 0.85 \\
\hline At least once a week & 1.28 & 0.34 & 1.97 & 0.77 \\
\hline Almost every day & 1.00 & & 1.00 & \\
\hline \multicolumn{5}{|c|}{ Frequency of listening to radio } \\
\hline Not at all & $0.24^{*}$ & 0.16 & 1.38 & 0.95 \\
\hline Less than once a week & $0.35^{* *}$ & 0.13 & 0.75 & 0.44 \\
\hline At least once a week & 0.66 & 0.18 & 1.10 & 0.36 \\
\hline Almost every day & 1.00 & & 1.00 & \\
\hline
\end{tabular}


background factors. Table 4 indicates that condomuse at first sexual initiation varied considerably according to the personal attributes of the respondents, particularly age, urban-rural residence, and region. As would be expected, the proportions of the respondents who reported condom-use at first sexual intercourse increased with age. For instance, $11 \%$ of the respondents aged 15-19 years reported condom-use at first sexual intercourse compared to $20 \%$ of those aged 20-24 years. The result indicates that condom-use at first sexual initiation tended to be higher among urban dwellers than rural dwellers. About 3 in 10 urban dwellers included in this analysis reported condom-use at the first sexual intercourse compared to $11 \%$ for those living in rural areas.

Table 4 reveals a large regional difference in condom-use at the first sexual intercourse among young never-married males in Nigeria. The table shows that more young never-married male respondents in the southern region used condom at sexual debut compared to those in the northtwo-fifths of the respondents in the southwest region used a condom at the first sexual intercourse compared to $8.2 \%$ among the respondents in the northeast region. The finding showed that childhood place of residence confirmed the notion of higher condom-use among those who had some urban contact where access to reproductive health services were more than their rural counterparts. Condom-use at the first sexual intercourse was associated with higher levels of education, better access to mass media (newspapers, television, and radio), and higher socioeconomic status as reflected in the wealth quintile (Table 4). The results of the multivariate analysis of the determinants of condom-use at sexual debut are shown in Table 5. The analysis for this behaviour was restricted to those who reported that they have had sex. An odds ratio of greater than one for a particular variable indicates that the respondents in that category were more likely to have had used a condom than were the respondents in the reference or excluded group of the correlate. Odds ratio of less than one implied that the respondents in that category were less likely to have had used a condom than were the respondents in the reference category, and odds ratios of one implied no difference in the likelihood of condom-use compared to the reference group.

The findings in Table 5 also reveal that region of residence, wealth quintile, and exposure to television and radio were the important determinants of premarital sex and emerged as the significant determinants of condom-use at the first sexual encounter. Among these factors were region of residence and frequency of listening to radio. Young never-married males living in the southwest part of Nigeria were six times more likely to have used a condom during their first sexual encounter than those residing in the north-central region. The odds of using a condom at the first sexual encounter were associated with frequency of listening to radio. For example, young never-married males who reported listening to radio at least once a week were almost eight times more likely to have used a condom at their first sexual encounter than their counterparts who had never listened to radio. Education was significantly associated with condom-use at the first sexual encounter among the Nigerian young never-married males. Young nevermarried males with post-secondary education were 7.5\% times more likely to have used a condom compared to their reference group (no education) during their first sexual encounter.

About two-fifths (38\%) of sexually-active young never-married males used a condom at the time of their last intercourse. Despite a high level of sexual activity among the young never-married males, the level of condom-use among them was low, an indication of high level of their vulnerability to STIs, including HIV. The results in Table 4 further reveal that condom-use during the most recent sexual encounter was higher among young never-married males who were educated, urban dweller, Christian, had urban exposure at childhood, those at the upper end of age-group (among young never-married males), high household socioeconomic status, and frequency of exposure to newspaper, television, and radio. The logistic regression in Table 5 also reveals that region, education, wealth quintile, exposure to television, and relationship of the last sex partners were significantly associated with condom-use at the last sexual encounter among the young nevermarried males in Nigeria.

\section{DISCUSSION}

This study found a high level of premarital sexual activity among the young never-married males. Age at initiation of sex remained low and current sexual activity high, although the personal and sensitive nature of questions on sexual activity make reports of age and level prone to deliberate misinformation. The results also suggest that a large proportion of young never-married males engage themselves in sexual intercourse without a condom, thus increasing their vulnerability to STIs 


\begin{tabular}{|c|c|c|c|c|}
\hline \multirow{2}{*}{ Characteristics/variable } & \multicolumn{2}{|c|}{ Use at first sex $(n=355)$} & \multicolumn{2}{|c|}{ Use during last sex $(n=355)$} \\
\hline & No. & $\%$ & No. & $\%$ \\
\hline \multicolumn{5}{|l|}{ Age-group (years) } \\
\hline $15-19$ & 126 & 10.6 & 90 & 30.8 \\
\hline $20-24$ & 278 & 19.9 & 236 & 40.4 \\
\hline \multicolumn{5}{|l|}{ Place of residence } \\
\hline Urban & 179 & 27.3 & 144 & 54.1 \\
\hline Rural & 225 & 11.1 & 182 & 27.6 \\
\hline \multicolumn{5}{|l|}{ Region of residence } \\
\hline North-central & 86 & 12.4 & 69 & 38.5 \\
\hline Northeast & 59 & 8.2 & 47 & 18.1 \\
\hline Northwest & 51 & 6.7 & 47 & 5.3 \\
\hline Southeast & 55 & 28.0 & 39 & 70.8 \\
\hline South-South & 71 & 11.5 & 55 & 42.0 \\
\hline Southwest & 82 & 40.0 & 69 & 63.1 \\
\hline \multicolumn{5}{|c|}{ Childhood place of residence } \\
\hline City & 65 & 29.2 & 57 & 54.3 \\
\hline Town & 136 & 23.9 & 110 & 43.9 \\
\hline Countryside & 202 & 8.3 & 158 & 27.5 \\
\hline \multicolumn{5}{|l|}{ Educational level } \\
\hline No education & 32 & 0.0 & 27 & 0.0 \\
\hline Primary & 89 & 8.8 & 70 & 18.1 \\
\hline Secondary & 255 & 17.0 & 205 & 43.0 \\
\hline Tertiary & 28 & 63.7 & 24 & 86.6 \\
\hline \multicolumn{5}{|l|}{ Religious affiliation } \\
\hline Catholic & 87 & 22.2 & 68 & 46.3 \\
\hline Protestant & 64 & 14.8 & 52 & 40.2 \\
\hline Other Christians & 99 & 16.9 & 75 & 49.8 \\
\hline Muslim & 150 & 15.8 & 128 & 27.0 \\
\hline Traditional/others & 4 & 0.0 & 3 & 0.0 \\
\hline \multicolumn{5}{|l|}{ Wealth quintile } \\
\hline First & 83 & 7.8 & 67 & 14.8 \\
\hline Second & 54 & 8.4 & 50 & 24.1 \\
\hline Third & 69 & 10.6 & 51 & 28.4 \\
\hline Fourth & 89 & 18.3 & 70 & 46.7 \\
\hline Fifth & 109 & 33.2 & 88 & 65.2 \\
\hline \multicolumn{5}{|c|}{ Frequency of reading newspapers or magazines } \\
\hline Never & 175 & 7.9 & 137 & 20.4 \\
\hline Less than once a week & 111 & 17.2 & 91 & 36.9 \\
\hline At least once a week & 82 & 19.0 & 68 & 54.1 \\
\hline Almost every day & 35 & 53.6 & 29 & 73.6 \\
\hline \multicolumn{5}{|c|}{ Frequency of watching television } \\
\hline Never & 85 & 6.2 & 71 & 7.9 \\
\hline Less than once a week & 102 & 14.0 & 84 & 37.5 \\
\hline At least once a week & 89 & 12.3 & 69 & 54.1 \\
\hline Almost every day & 127 & 29.0 & 101 & 57.3 \\
\hline \multicolumn{5}{|c|}{ Frequency of listening to radio } \\
\hline Never & 18 & 5.9 & 16 & 13.0 \\
\hline Less than once a week & 36 & 18.9 & 26 & 49.9 \\
\hline At least once a week & 82 & 15.1 & 64 & 24.8 \\
\hline Almost every day & 267 & 18.0 & 219 & 41.2 \\
\hline
\end{tabular}


Table 5. Logit regression results for correlates of young never-married males aged 15-24 years-reports of condom-use at the first and last sexual intercourse, Nigeria, 2003

\begin{tabular}{|c|c|c|c|c|}
\hline \multirow{2}{*}{ Characteristics } & \multicolumn{2}{|c|}{$\begin{array}{l}\text { Condom-use at first } \\
\text { intercourse }\end{array}$} & \multicolumn{2}{|c|}{$\begin{array}{l}\text { Condom-use at last } \\
\text { intercourse }\end{array}$} \\
\hline & Odds ratio & $\begin{array}{c}\text { Standard } \\
\text { error }\end{array}$ & Odds ratio & $\begin{array}{l}\text { Standard } \\
\text { error }\end{array}$ \\
\hline \multicolumn{5}{|l|}{ Age-group (years) } \\
\hline $15-19$ & 0.61 & 0.26 & 0.67 & 0.23 \\
\hline $20-24$ & 1.00 & & 1.00 & \\
\hline \multicolumn{5}{|l|}{ Place of residence } \\
\hline Urban & & & 1.40 & 0.52 \\
\hline Rural & & & 1.00 & \\
\hline \multicolumn{5}{|l|}{ Region of residence } \\
\hline North-central & 1.00 & & 1.00 & \\
\hline Northeast & 1.32 & 1.14 & 0.39 & 0.23 \\
\hline Northwest & 1.14 & 0.96 & 0.19 & 0.18 \\
\hline Southeast & 1.96 & 1.58 & 1.97 & 1.07 \\
\hline South-South & 1.67 & 1.34 & 0.89 & 0.44 \\
\hline Southwest & $6.00^{\star \star}$ & 3.90 & $2.58^{*}$ & 1.26 \\
\hline \multicolumn{5}{|l|}{ Educational level } \\
\hline Below secondary & 1.00 & & 1.00 & \\
\hline Secondary & 1.98 & 1.10 & $2.82^{*}$ & 1.25 \\
\hline Post-secondary & $7.49^{\star \star}$ & 5.88 & $8.88^{\star *}$ & 6.67 \\
\hline \multicolumn{5}{|l|}{ Religious affiliation } \\
\hline Catholic & 1.18 & 0.80 & 0.69 & 0.42 \\
\hline Protestant & 0.77 & 0.46 & 1.04 & 0.55 \\
\hline Other Christians & 0.80 & 0.48 & 1.07 & 0.52 \\
\hline Muslim & 1.00 & & 1.00 & \\
\hline \multicolumn{5}{|l|}{ Wealth quintile } \\
\hline First & 1.00 & & 1.00 & \\
\hline Second & 0.70 & 0.65 & $3.13^{*}$ & 1.74 \\
\hline Third & 0.60 & 0.51 & 2.61 & 1.44 \\
\hline Fourth & 0.82 & 0.68 & $3.67^{*}$ & 2.39 \\
\hline Fifth & 0.69 & 0.64 & 2.70 & 1.90 \\
\hline \multicolumn{5}{|c|}{ Frequency of reading newspapers or magazines } \\
\hline Not at all & 1.00 & & 1.00 & \\
\hline Less than once a week & 1.67 & 0.80 & 0.89 & 0.35 \\
\hline At least once a week & 1.36 & 0.73 & 1.98 & 0.93 \\
\hline Almost every day & $5.46^{\star \star}$ & 3.63 & 3.73 & 2.73 \\
\hline \multicolumn{5}{|c|}{ Frequency of watching television } \\
\hline Not at all & 1.00 & & 1.00 & \\
\hline Less than once a week & 1.74 & 1.05 & $5.04^{\star \star}$ & 2.68 \\
\hline At least once a week & 1.17 & 0.92 & 2.90 & 1.96 \\
\hline Almost every day & 1.62 & 1.25 & 2.13 & 1.45 \\
\hline \multicolumn{5}{|l|}{ Frequency of listening to radio } \\
\hline Not at all & 1.00 & & 1.00 & \\
\hline Less than once a week & $7.74^{*}$ & 8.21 & 6.22 & 7.42 \\
\hline At least once a week & 3.62 & 3.70 & 0.88 & 1.07 \\
\hline Almost every day & 2.17 & 2.20 & 1.92 & 2.20 \\
\hline \multicolumn{5}{|l|}{ Childhood place of residence } \\
\hline City & 2.32 & 1.31 & & \\
\hline Town & $2.37^{*}$ & 1.06 & & \\
\hline Countryside & 1.00 & & & \\
\hline \multicolumn{5}{|c|}{ Relationship of the last sex partners } \\
\hline Causal friend/sex workers & & & $6.36^{\star *}$ & 2.88 \\
\hline Spouse or girlfriend/fiancée & & & 1.00 & \\
\hline
\end{tabular}


and unwanted pregnancies. For instance, the level of condom-use at sexual debut was $17 \%$, and $38 \%$ used a condom during their last sexual act. The low level of condom-use at sexual debut is comparable with earlier analysis in Nigeria (10) and other subSaharan African countries (29-30). Results revealed that initiation of sexual activity and condom-use are influenced by arrays of background, social and environmental factors $(9,20-22)$.

The results of the present study revealed that the young never-married males who were at the greatest risk of adverse reproductive health behaviours appeared to be from families of low economic status, those who resided in rural areas, and those who lived in the countryside during their childhood. This could be explained by the fact that the majority of the young never-married males from these backgrounds might have been denied sex education, thus making them ignorant of what they needed to do for protection. In addition, the parents, the family, and the community members expect that social and traditional norms should be adhered to strictly; however, the influence of sociocultural norms are being eroded as a result of poverty and education, thereby often exposing them to risky behaviour. The social and traditional norms which prohibited sexual intercourse before marriage are being eroded due to increased age at first marriage being observed (3) and exposure to mass-media influence (31-32). Frequent exposure to mass media, attaining higher levels of education, and growing older appeared to be protective factors against unprotected sex, although the young males with these characteristics were more sexually experienced.

The regional patterns of sexual behaviour (ever had sexual intercourse and used a condom) found in this study suggest that ethnicity may be an important factor to be considered when studying adolescents or young people's sexuality and sexual behaviour. However, this influence of cultural norms may be changing due to globalization and education, especially in cities where people are more likely to abandon traditions because of the heterogeneity of populations. Still for many Nigerians, ethnic affiliation, which is usually a regional element, means shared language and norms governing behaviour and sexuality issues. The results of this study support the view that condom-use and age at sexual debut in Nigeria are a function of varied sociocultural factors, including religion, level of exposure to formal education, and urban-rural residence among others.
Apart from the regional differences in sexual behaviour observed in the study, several results showed the association between the characteristics of young never-married males and condom-use. Compared to rural dwellers, those residing within urban environments were more sexually experienced and more likely to use a condom at the first coitus. The high level of sexual activity among the urban young never-married males can be seen in the context of a permissive environment which favours the attraction and interaction of youths of opposite sex and which, therefore, exposes them to sexual contact. The same factor, however, serves as a protective mechanism by encouraging the use of a condom due to high level of awareness on the intrinsic worth of condom-use. The result of the study also indicates that growing older is associated with sexuality and condom-use among young never-married males in Nigeria. The finding of the study supports the view that sexual activity and condom-use are functions of household socioeconomic status (wealth quintile).

The results of the study shed further light with regard to the challenges facing programmes aimed at improving the reproductive health situation of adolescents and young never-married males in Nigeria and opportunities for intervention. One major challenge is the sizeable number and diverse nature of factors that appeared to influence behaviour of young never-married males. Some of these were particular characteristics of the environment in which they are reared. Therefore, a single, easyto-implement intervention is unlikely to provide a solution to the high rate of sexual activity and its consequences of teenage pregnancy and vulnerability to STI and HIV/AIDS transmission in Nigeria. This is consistent with the findings of a previous study which revealed that, when in a given setting and a multitude of correlates exists, each having a small impact on sexual behaviour rather than a few correlates, each having a large impact, a single 'magic bullet' is unlikely to be found to change sexual behaviour of adolescents significantly (33).

\section{Conclusions}

The results of the study have important policy implications. Since the factors associated with sexual behaviour and condom-use among never-married young Nigerian males vary according to place of residence, region of residence, exposure to mass media, and wealth quintile, programmes may need to position intervention differently for different target populations. The study established that 
there is a high level of unprotected premarital sex, thus making the population under study vulnerable to HIV infection. In addition, an unwanted pregnancy could lead to termination of education; as a result, young women and men could face a bleak economic and social future. Therefore, behaviour-change communication should be strengthened with extensive education on sexual abstinence and safe sexual behaviour through culturally-appropriate messages as is currently undertaken by various non-governmental organizations in the country. In particular, more efforts should be made to reach young never-married males in the countryside, who typically had earlier sexual debut and also tended to be more sexually active, with adequate information on behaviour change, prevention of unwanted pregnancies, and protection from STIs, including HIV/AIDS.

\section{ACKNOWLEDGEMENTS}

The authors acknowledge the helpful comments of Dr. Bamikale Feyisetan of the Academy of Education Development, USA, in the preparation of this article. In addition, the authors thank the Marco International and National Population Commission, Nigeria, for making the data of the Nigeria Demographic and Health Survey available for use.

\section{REFERENCES}

1. Singh S, Wulf D, Samara R, Cuca YP. Gender differences in the timing of first intercourse: data from 14 countries. Int Fam Plann Perspect 2000;26:21-8, 43.

2. Forste RT, Heaton TB. Initiation of sexual activity among female adolescents. Youth Soc 1988;19:250-68.

3. Gueye M, Castle S, Konate MK. Timing of first intercourse among Malian adolescents: implications for contraceptive use. Int Fam Plann Perspect 2001;27:5662,70 .

4. Rwenge M. Sexual risk behaviors among young people in Bamenda, Cameroon. Int Fam Plann Perspect 2000;26:118-23, 130.

5. Omorodion, FI, Olusanya O. The social context of reported rape in Benin city, Nigeria. Afr J Reproduct Health 1998;2:37-43.

6. Ajuwon AJ, Olley BO, Akin-Jimoh I, Akintola O. Experience of sexual coercion among adolescents in Ibadan, Nigeria. Afr J Reproduct Health 2001;5:120-31.

7. Slap GB, Lot L, Huang B, Daniyam CA, Zink TM, Succop PA. Sexual behaviour of adolescents in Nigeria: cross sectional survey of secondary school students. Br J Med 2003;326:1-6.

8. Magnani RJ, Seiber EE, Gutierrez EZ, Vereau D. Correlates of sexual activity and condom use among secondary-school students in urban Peru. Stud Fam Plann 2001;32:53-66.

9. Oyediran KA, Ishola GP, Adewuyi AA. Knowledge of possible pregnancy at first coitus: a study of in-school adolescents in Ibadan, Nigera. Biosoc Sci 2002;34: 233-48.

10. Mberu BU. Protection before the harm: the case of condom use at the onset of premarital sexual relationship among youths in Nigeria. Afr Popul Stud 2008;23:57-83.

11. Archibong EI. Illegal induced abortion-a continuing problem. Int J Obstetr Gynaecol 1991;34:261-5.

12. Brabin L, Kemp J, Obunge OK, Ikimalo J, Dolimore $\mathrm{N}$, Odu NN et al. Reproductive tract infections and abortion among adolescent girls in rural Nigeria. Lancet 1995;345:270-1.

13. Ekweozor CC, Olaleye OD, Tomori O, Saliu I, Essien EM, Bakare RA et al. Clinical epidemiology of STD patients seen in Ibadan. Afr J Med Sci 1995;24:321-7.

14. Bello CSE, Egah DZ, Okwori EE, Nwokedi EE, Katung PY, Zoakah AI et al. Sexually transmitted diseases (STD): six years experience in Jos Teaching Hospital. Niger J Med 1997;6:83-6 .

15. Arowojolu AO, Ilesanmi AO, Roberts OA, Okunola MA. Sexuality, contraceptive choice and AIDS awareness among Nigerian undergraduates. Afr J Reproduct Health 2002;6:60-70.

16. Isiugo-Abanihe IM, Isiugo-Abanihe UC, Ofrey R. Teenage reproductive health problems in the Riverine areas of Nigeria: the Nembe experience. In: Proceeding of the Third African Population Conference, Durban, South Africa, 6-10 December 1999. V. V. Compiled by Union for African Population Studies. Dakar: Union for African Population Studies, 1999:393-411.

17. Moronkola OA, Idris OM. Sexual health knowledge, determinants of sexual behaviour and use of contraceptives among female secondary school students in Ibadan, Nigeria. Niger School Health J 2000;12:27-35.

18. Esiet A. Building support for adolescent health education and services in Nigeria: reflections from the experience of Action Health Incorporated (AHI). New York, NY: International Women's Health Coalition, 2003. 4 p.

19. Nichols D, Lapido OA, Paxman JM, Otolorin EO. Sexual behavior, contraceptive practice, and reproductive health among Nigerian adolescents. Stud Fam Plann 1986;17:100-6.

20. Feyisetan JB, Pebley AR. Premarital sexuality in urban nigeria. Stud Fam Plann 1989;20:343-54.

21. Makinwa-Adebusoye P. Sexual behavior, reproductive knowledge and contraceptive use among young urban Nigerians. Int Fam Plann Perspect 1992;18:6670. 
22. Isiugo-Abanihe UC, Oyediran K. Household socioeconomic status and sexual behaviour among Nigerian female youth. Afr Populat Stud 2004;19:81-98.

23. Brieger W, Delano G, Lane C, Oladimeji O Oyediran K. West African Youth Initiative: outcome of a reproductive health education program. I Adolesc Health 2001;29:436-46.

24. Radhakrishna A, Gringle R, Greenslade F. Adolescent women face triple jeopardy: unwanted pregnancy, HIV/AIDS and unsafe abortion. Women's Health J 1997;2:53-62.

25. Rosenthal SL, von Ranson KM, Cotton S, Biro FM, and Mills L. Sexual initiation: predictors and developmental trends. Sex Transm Dis 2001;28:527-32.

26. National Population Commission. Nigeria demographic and health survey 2003. Carlverton, MD: National Population Commission, 2004. 349 p.

27. Odimegwu C. Influence of religion on adolescent sexual attitudes and behavior among Nigerian uni- versity students: affiliation or commitment? Afr Reproduct Health 2005;9:125-40.

28. Zaleski EH, Schiaffino KM. Religiosity and sexual risktaking behavior during the transition to college. $J$ Adolesc Health 2000;23:223-7.

29. William KA, Alexander CS. Determinants of condom use to prevent HIV infection among youth in Ghana. J Adolesc Health 1999;24:63-72.

30. Ndola PE, Vahidnia E, Fraser A. Gender and relationship differences in condom use among 15-24 years olds in Angola. Int Fam Plann Perspect 2005;31:192-9.

31. Ward M. Hansbrough E, Walker E. Controbutions of music video exposure to black adolescents' gender and sexual schema. J Adolesc Res 2005;20:143-66.

32. Brown JD. Mass media influences on sexuality. J Sex Res 2002;39:42-5.

33. Babalola, S., Awasum D, Quenum-Renaud B. The correlates of safe sex practices among Rwanda youth: a positive deviance approach. Afr J AIDS Res 2002;1:11-21. 